\title{
Childhood Trauma and Resilience: Vulnerabilities to Develop Crack/Cocaine Dependence
}

\author{
Anne Orgler Sordi ${ }^{*}$, Simone Hauck ${ }^{1}$, Helen Laitano ${ }^{1}$, Silvia Halpern ${ }^{1}$, Silvia Schuch ${ }^{1}$, Felix Kessler ${ }^{1,2}$, Lisia Von Diemen ${ }^{1}$, Joana Narvaez ${ }^{1}$, \\ Luciano SP Guimarães ${ }^{3}$ and Flávio Pechansky ${ }^{1,2}$ \\ ${ }^{1}$ Center for Drug and Alcohol Research, Hospital de Clínicas de Porto Alegre (HCPA). Universidade Federal do Rio Grande do Sul (UFRGS). Rua Prof. Álvaro Alvim 400, \\ CEP 90420-020, Porto Alegre, RS, Brazil \\ ${ }^{2}$ Department of Legal Medicine and Psychiatry, UFRGS. Rua Ramiro Barcelos 2350, CEP 90035-903, Porto Alegre, RS, Brazil \\ ${ }^{3}$ Biostatistics Department, HCPA. Rua Ramiro Barcelos 2350, CEP 90035-903, Porto Alegre, RS, Brazil
}

\begin{abstract}
Background: Crack cocaine dependence is a health problem of epidemic proportions and there is lack of evidence concerning vulnerability factors that could lead to crack cocaine use. The aim of this study is to investigate characteristics of resilience in a group of crack cocaine users and its association with childhood trauma and PTSD.

Method: This is a case-control study in which we evaluated 218 crack cocaine inpatients users and 215 healthy controls, recruited from the capital city of the southern State of Brazil. Childhood Trauma was evaluated with the Childhood Trauma Questionnaire; resilience was evaluated with the Resilience Scale; and post-traumatic stress disorder (PTSD) was evaluated with the Mini-International Neuropsychiatric Interview.

Results: Childhood trauma was significantly higher among crack cocaine users in all trauma domains $(p<0.001)$, except for sexual abuse. Most resilience scores was lower among crack cocaine users $(p<0.01)$. Having higher scores of childhood trauma and lower scores of resilience increase the odds to become a crack cocaine user $(p<0.001)$, despite the diagnosis of PTSD.
\end{abstract}

Discussion: Childhood trauma appears to be a risk factor to become a crack cocaine user while resilience features may be a protection factor. To understand factors of vulnerabilities in this population is important for the development of more efficacious treatment and preventive strategies.

Keywords: Childhood trauma; Crack cocaine; PTSD; Resilience; Substance abuse

\section{Introduction}

Substance abuse is a health problem of epidemic proportions, which interferes in all segments of society and is related to individual vulnerabilities and environment [1]. Crack cocaine use, in particular, poses a challenge for health professionals and investigators since a wide proportion of users have little motivation for treatment, and its use leads to impairment in many psychosocial aspects such as unemployment, cognitive impairment and risk for infectious diseases due to risky sexual behavior [2-5]. Although its prevalence is not high among other types of drug use - life use is around $4,2 \%$ - it has high potential to cause dependence, and its abuse is associated with a number of negative outcomes for the individual, families and community, including death due to violence and criminal behavior [6,7]. However, there is a group of patients that develop a more stable pattern of use and are somehow more resilient to the impairment caused by this substance [8].

Substance abuse, especially cocaine dependence, is highly associated with childhood trauma and Post Traumatic Stress Disorder (PTSD) $[9,10]$. At the same time that traumatic events increase vulnerability to experimentation of psychoactive substances, drug use creates an environment that facilitates the onset of the aforementioned events, which can also affect brain structures and function. When trauma takes place during early development, it becomes a risk factor for the onset of a wide range of psychological manifestations such as major depression, anxiety, eating disorders, bipolar disorder and substance abuse $[11,12]$. Moreover, individuals with severe drug abuse and PTSD have an increased risk of relapse, and often these substances are used for self-medication, especially because during abstinence trauma reliving symptoms could be increased [13]. Therefore, the investigation of childhood trauma and PTSD must be addressed during treatment.

Literature demonstrates that there are different types of childhood trauma exposure (i.e., emotional, physical, and sexual abuse; emotional and physical neglect) which are associated with the risk of developing psychiatric comorbidity among alcoholic patients [14]. These events may lead to a change in the level of awareness of their environment, and an increasing inability to cope with everyday life stressors [15]. The high prevalence of a hostile environment - not unusual in the crack cocaine population - such as social disorganization, unfavorable economic conditions and violence, emphasizes the predisposition to traumatic events among a population that could be already vulnerable to the development of PTSD [16]. Studies suggest that to evaluate the high co-occurrence PTSD and substance abuse is fundamental to understand the mechanisms of substance dependence, as well as to improve treatment programs [17]. For instance, the history of stressful life events could increase oxidative stress in neurons, and lead to alterations in the hypothalamus- hypophysis adrenal axis (HAA-axis) which could interfere in the way brain respond to drug exposure.

*Corresponding author: Anne Orgler Sordi, Center for Drug and Alcoho Research, Hospital de Clínicas de Porto Alegre (HCPA). Universidade Federa do Rio Grande do Sul (UFRGS). Rua Prof. Álvaro Alvim 400, CEP 90420-020, Porto Alegre, RS, Brazil, Tel: (813) 931-3345; E-mail: annesordi@yahoo.com.br

Received: October 20, 2015; Accepted: November 24, 2015; Published November 27, 2015

Citation: Sordi AO, Hauck S, Laitano H, Halpern S, Schuch S, et al. (2015) Childhood Trauma and Resilience: Vulnerabilities to Develop Crack/Cocaine Dependence. J Alcohol Drug Depend 3: 227. doi:10.4172/23296488.1000227

Copyright $\odot 2015$ Sordi AO, et al. This is an open-access article distributed under the terms of the Creative Commons Attribution License, which permits unrestricted use, distribution, and reproduction in any medium, provided the original author and source are credited. 
On the other hand, despite all the impairment related to traumatic events, some individuals are able to develop effective coping responses, achieving success in one or more important areas of life, such as relationship with others, education, and family, which stands for a positive process of adaptation in a context of adversity and high risk. While coping is related to the development of strategies to use in case of adverse events, resilience is a concept related to the ability of dealing with a traumatic event and evolving with it, in a healthy and adaptive way [18-20]. Some protective factors during early childhood - like having caring parents, education, the absence of childhood abuse or neglect, and a less conflicted family environment, are promoters of resilience when it comes to later exposure to risky situations such as drug experimentation, or overcoming traumatic events [21,22].

The assessment of resilience, to be valid, must be understood within the cultural context in which it is ascertained [23]. Studies that evaluate resilience in substance use disorder often use different parameters to measure it, such as time until relapse or subjective perceptions, but there are no studies evaluating resilience among cocaine users with valid psychometric scales [24-26]. Having a valid measurement of resilience is an important issue in substance abuse studies, since literature suggests that resilience could play an important role in reducing relapse in alcohol and other psychoactive drugs, being considered a protective factor for substance use [27]

Understanding how resilience is expressed among crack cocaine users and its relationship to childhood abuse and the occurrence of PTSD could contribute for the improvement of treatment efficacy and the development of more appropriate public policies [27]. There are only a few studies evaluating resilience in substance users, and this is the first study to evaluate resilience in a sample of crack cocaine users. Therefore, the aim of this study was to investigate characteristics of resilience in a group of crack cocaine users and its association with childhood trauma and PTSD.

\section{Method}

\section{Participants and procedures}

We recruited 218 crack cocaine users at the age of 18 years or more with positive urine cocaine test (Bioeasy cocaine test, Alere ${ }^{\mathrm{mm}}$, Belo Horizonte, Brazil) at Hospital São Pedro, a public psychiatric hospital that has a specialized unit for the treatment of addiction located in Porto Alegre, southern Brazil. All crack cocaine users where interviewed during intern treatment. Subjects were excluded if they were considered unable to participate based on clinical and psychiatric examination (ex. severe psychosis or depression) or a measured intelligence quotient $<70$, or refused to sign a written informed consent. Patients were recruited and invited to participate in the study at the first day of hospitalization or as soon as they were able to understand study objectives. Interviews were conducted between the fifth and seventh day of detoxification to circumvent potential cognitive impairment on the first days of hospitalization.

For the control group, 215 non-crack/cocaine users, 18 years or more, were recruited from records of a primary care center from neighborhoods similar to the crack users' original surroundings (described elsewhere) [28]. Inclusion criteria were to be male and to be at least 18 years old. Controls were excluded if they reported cocaine use in the last year, had positive urine screening for cocaine, or refused to sign a written informed consent. Controls were visited at their home because it was more comfortable for them, since many of them were regular workers and didn't have time to go elsewhere for the interview.
There, they and asked if they would accept to participate in the study. If so, they answer a screening questionnaire to exclude if they used cocaine in the last year and also had a urine screening test for cocaine use at the time. All subjects who self-reported not to be a crack/cocaine user and presented a negative urine test for cocaine were interviewed.

All data were collected by psychologist undergraduate students that were trained and supervised weekly by a panel of experts. The equivalence in the application of instruments achieved a kappa> 0.8 among the interviewers. Data were collected from April 2011 to February 2012.

Information about drug use was assessed by the Addiction Severity Index- 6th Version (ASI-6), validated for Brazilian Portuguese [29] Intelligence quotient was estimated using vocabulary and block design tests from the Wechsler Adult Intelligence Scale - third edition (WAIS III) which was validated to the Brazilian Portuguese [30]. The diagnostic of other psychiatric disorders was assessed by the Mini International Neuropsychiatric Interview (MINI) - a semi-structured interview that is based on the DSM IV diagnosis. It has been translated into more than 30 different languages and is validated for the Brazilian population [31].

\section{Measures}

Resilience: Resilience scores were evaluated by the Resilience Scale developed by Wagnild and Young, which measures different levels of adaptation in relation to important life events. It consists of 25 Likert-type questions that score 3 factors for resilience: 1) ability to solve situations and personal values that give meaning to life; 2) independence and determination; 3 ) self-confidence and adaptation. It has been translated into the Portuguese language and validated for the Brazilian population [32].

Childhood trauma: Childhood trauma was assessed by the Childhood Trauma Questionnaire (CTQ). This is a Likert scale that has 5 sub-scales to evaluate: 1) Emotional Abuse; 2) Physical Abuse; 3) Sexual Abuse; 4) Emotional Neglect; 5) Physical Neglect. It has been validated for the Brazilian population, although there is no cutoff for the trauma scores [33]. As we do not have a cutoff score for our population, we chose to analyze data as a continuous variable.

Although the CTQ and Resilience Scale are self-repot questionnaires, we chose to apply all the instruments to avoid differences in interpretation due to literacy problems.

\section{Statistics}

A descriptive analysis was conducted to represent the sociodemographic variables separated by case and control groups. Absolute and relative frequency was performed for the categorical variables, and the chi-square test was used to compare these variables within groups. For quantitative variables, initially, the normality Shapiro-Wilk test was performed. For variables with normal distribution the description was represented by mean and standard deviation, and the $t$ test for independent samples was performed when comparing the groups. Variables that showed an asymmetric distribution are represented by quartiles. For comparison between groups we used non-parametric Mann-Whitney test. Quantitative variables were correlated using Spearman's correlation. Variables of trauma and resilience were related to cases and controls using Poisson regression. In a second model the diagnosis of PTSD subjects was entered to verify its influence. Analyses were performed using SPSS v.18. The significance level was set at 0.05 . 
Citation: Sordi AO, Hauck S, Laitano H, Halpern S, Schuch S, et al. (2015) Childhood Trauma and Resilience: Vulnerabilities to Develop Crack/ Cocaine Dependence. J Alcohol Drug Depend 3: 227. doi:10.4172/23296488.1000227

Page 3 of 6

\section{Ethics}

The study was approved by the Institutional Review Board and Ethics Committee of the Hospital de Clinicas de Porto Alegre and of the Hospital São Pedro. All participants provided written informed consents.

\section{Results}

Crack users and controls were mostly male and Caucasian. Crack users had fewer years of education $(p<0.001)$. Prevalence of all psychiatric disorders was higher among crack users, especially post traumatic stress disorder (PTSD) and antisocial personality disorder (ASPD). These findings are shown in Table 1.

Considering the resilience factors, controls presented significantly higher ability to solve situations and personal values that give meaning to life as well as independence and determination. These findings are shown in Figure 1.

Except for sexual abuse, which did not show a significant difference between cases and controls, all other subtypes of childhood trauma were higher among crack cocaine users. These findings are shown in Figure 2 .

In order to see how childhood trauma relates to the construct of resilience, we considered the whole sample of the study, and found that ability to solve situations and personal values that give meaning to life have an inverse correlation with emotional abuse and neglect, and independence and determination had an inverse correlation to emotional neglect. These findings are shown in Table 2.

When we analyzed all the domains of childhood abuse and resilience among those with and without PTSD, we found a significant difference in levels of emotional abuse and emotional neglect, as well as all levels of resilience factors among crack cocaine users. These findings are shown in Table 3.

We found no significant difference among controls with and without PTSD, probably because there were only two subjects among controls who reported to have PTSD. A logistic regression was performed to evaluate how every type of childhood trauma and resilience factors increase or decrease the chance of being a crack cocaine user in the sample, considering also the diagnosis of PTSD. Results showed that childhood trauma increases the odds of being a crack cocaine user despite the diagnosis of PTSD. On the other hand, resilience factor 1 and 2 turned out to be a factor of protection, increasing the odds of not becoming a crack cocaine user. These findings are shown in Table 4.

\section{Discussion}

This study aimed to investigate the characteristics of resilience in a group of crack cocaine users and its association with childhood trauma and PTSD. Our results demonstrate that there is an inverse correlation between resilience and different types of childhood trauma. When we evaluate these two constructs within the overall study sample, we found that emotional childhood traumas are inversely associated with resilience aspects related to personal competence, self-acceptance, acceptance of life, independence and determination. In addition, crack cocaine users reported to have had more intense childhood trauma (except for sexual abuse) and lower levels of some aspects of resilience when compared to healthy controls. We didn't find a difference between cases and controls in relation to sexual abuse because this measure is probably underestimated in our study. It is known that among substance abusers, sexual abuse is a major issue with a high prevalence,

\begin{tabular}{|c|c|c|c|c|}
\hline & \multirow{2}{*}{$\begin{array}{c}\text { Cases }(n=218) \\
n(\%)\end{array}$} & \multirow{2}{*}{$\begin{array}{c}\text { Control (215) } \\
\mathrm{n}(\%)\end{array}$} & \multirow[t]{2}{*}{$\mathrm{p}$} \\
\hline & & & & \\
\hline Gender & Male & $208(95.4)$ & $211(98.1)$ & 0.183 \\
\hline $\mathrm{Age}^{*}$ & & $29.5(8.1)$ & $29.1(7.9)$ & 0.605 \\
\hline \multirow[t]{4}{*}{ Race } & Caucasian & $140(64.2)$ & $137(64.3)$ & \\
\hline & & & & 0.106 \\
\hline & African American & $42(19.3)$ & $28(13.1)$ & \\
\hline & Other & $36(16.5)$ & $48(22.5)$ & \\
\hline \multirow[t]{5}{*}{ Schooling } & Non Alphabetized & $1(0.5)$ & 0 & $<0.001$ \\
\hline & 1-4th grade & $10(4.7)$ & $12(5.7)$ & \\
\hline & $5-8$ th grade & $83(39.0)$ & $52(24.5)$ & \\
\hline & High School & $78(36.6)$ & $121(57.1)$ & \\
\hline & College & $41(19.2)$ & $27(12.7)$ & \\
\hline & & $(\%)$ & (\%) & \\
\hline \multicolumn{2}{|c|}{$\begin{array}{c}\text { Drug use Disorder (other than } \\
\text { crack) }\end{array}$} & 54 & 13 & $<0.001$ \\
\hline & PTSD & 11 & 0.9 & $<0.001$ \\
\hline \multicolumn{2}{|c|}{ Major Depression } & 28 & 6.2 & $<0.001$ \\
\hline \multicolumn{2}{|c|}{ Alcohol use disorder } & 34.6 & 8.2 & $<0.001$ \\
\hline \multicolumn{2}{|c|}{ Any anxiety disorder } & 25.5 & 5.3 & $<0.001$ \\
\hline \multicolumn{2}{|c|}{ ASPD } & 41.7 & 4.8 & $<0.001$ \\
\hline \multicolumn{2}{|c|}{ Bipolar Disorder } & 12 & 4.8 & $<0.001$ \\
\hline
\end{tabular}

"Medium (SD)

Note: For categorical variables, the chi-square test was used for comparison among groups. For variables with normal distribution we performed the test for independent samples when comparing the groups. Psychiatric disorders were evaluated by the Mini International Neuropsychiatric Interview. Table 1: Sociodemographic variables.

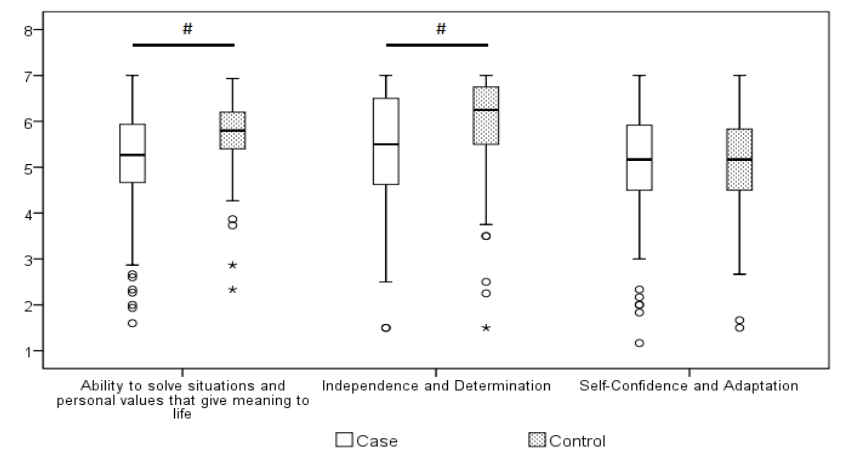

Mann-Whitney Test

$\# p<0.01$

Figure 1: Resilience among crack users and controls.

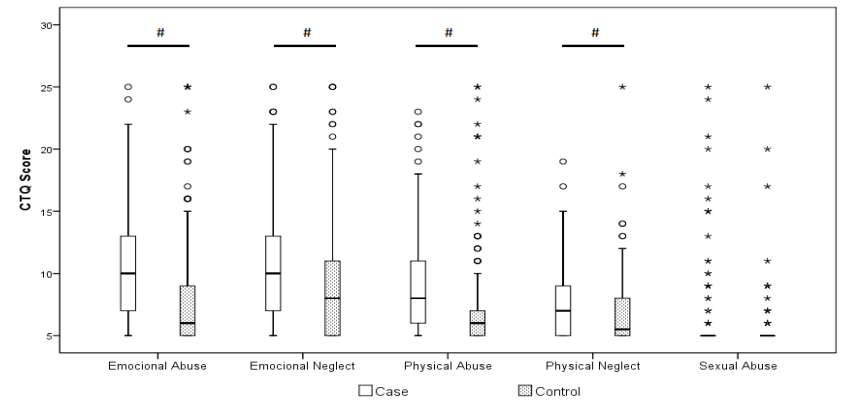

Mann-Whitney Test.

\# $\mathrm{p}<0.001$

Figure 2: Childhood trauma among crack users and controls. 


\begin{tabular}{|c|c|c|c|}
\hline & \multicolumn{3}{|c|}{ Resilience } \\
\cline { 2 - 4 } & Factor1 & Factor2 & Factor3 \\
\hline Emocional_Abuse & $-0.193^{*}$ & -0.068 & -0.006 \\
\hline Physical_Abuse & -0.051 & -0.034 & 0.099 \\
\hline Sexual_Abuse & -0.057 & -0.037 & -0.016 \\
\hline Emocional_Neglect & $-0.152^{*}$ & $-0.147^{*}$ & -0.042 \\
\hline Physical_Neglect & -0.050 & -0.089 & 0.084 \\
\hline
\end{tabular}

Factor 1: ability to solve situations and personal values that give meaning to life; Factor 2: independence and determination; Factor 3: self-confidence and adaptation.

Spearman Correlation Test.

$p<0.001$

Table 2: Correlation between trauma and resilience.

\begin{tabular}{|c|c|c|c|}
\hline & \multicolumn{3}{|c|}{ PTSD } \\
\cline { 2 - 4 } & $\begin{array}{c}\text { Yes (n=22) } \\
\text { Median (q1;q2) }\end{array}$ & $\begin{array}{c}\text { No (n=186) } \\
\text { Median (q1; q2) }\end{array}$ & p \\
\hline Emocional_Abuse & $11.5[8.75 ; 14.25]$ & $9[6 ; 13]$ & 0.018 \\
\hline Physical_Abuse & $8.5[6.75 ; 13.5]$ & $8[6 ; 11]$ & 0.148 \\
\hline Sexual_Abuse & $5[5 ; 11.5]$ & $5[5 ; 5]$ & 0.1 \\
\hline Emocional_Neglect & $12[9 ; 16]$ & $10[7 ; 13]$ & 0.042 \\
\hline Physical_Neglect & $7[5 ; 12.25]$ & $7[5 ; 9]$ & 0.503 \\
\hline Resilience Factor 1 & $4.57[3.78 ; 5.2]$ & $5.4[4.73 ; 6]$ & 0.001 \\
\hline Resilience Factor 2 & $5[4.18 ; 5.75]$ & $5.5[4.75 ; 6.5]$ & 0.038 \\
\hline Resilience Factor 3 & $4.17[3.79 ; 5.08]$ & $5.17[4.5 ; 6]$ & 0.002 \\
\hline
\end{tabular}

Factor 1: ability to solve situations and personal values that give meaning to life; Factor 2: independence and determination; Factor 3: self-confidence and adaptation.

Mann-Whitney Test.

Significance 2-tailed: 0, 05

Table 3: Childhood trauma and resilience among crack users with and without PTSD.

\begin{tabular}{|c|c|c|c|c|}
\hline & $\begin{array}{c}\text { Crack cocaine } \\
\text { users (n=218) } \\
\text { OR* [q1; q2] }\end{array}$ & $\mathbf{p}$ & $\begin{array}{c}\text { Crack cocaine users } \\
\text { with PTSD (n=22) } \\
\text { OR* }^{*} \text { [q1; q2] }\end{array}$ & $\mathbf{p}$ \\
\hline Emocional_Abuse & $1.15[1.1 ; 1.21]$ & $<0.001$ & $1.7[0.99 ; 4.56]$ & 0.158 \\
\hline Physical_Abuse & $1.13[1.07 ; 1.19]$ & $<0.001$ & $0.920[0.71 ; 1.22]$ & 0.510 \\
\hline Sexual_Abuse & $1.1[1.02 ; 1.22]$ & 0.033 & $\mathrm{x}$ & \\
\hline Emocional_Neglect & $1.08[1.03 ; 1.13]$ & 0.001 & $1.11[0.82 ; 1.77]$ & 0.566 \\
\hline Physical_Neglect & $1.13[1.05 ; 1.23]$ & 0.001 & $1.23[0.79 ; 3.17]$ & 0.495 \\
\hline Resilience Factor 1 & $0.05[0.34 ; 0.58]$ & $<0.001$ & $\mathrm{x}$ & \\
\hline Resilience Factor 2 & $0.64[0.53 ; 0.77]$ & $<0.001$ & $\mathrm{x}$ & \\
\hline Resilience Factor 3 & $0.95[0.79 ; 1.14]$ & 0.564 & $\mathrm{x}$ & \\
\hline
\end{tabular}

Factor 1: ability to solve situations and personal values that give meaning to life; Factor 2: independence and determination; Factor 3: self-confidence and adaptation.

Logistic Regression

$\mathrm{x}$ : Statistical analysis were not able to be performed because of the small number of crack cocaine users who reported to have PTSD.

OR: Odds Ratio

Table 4: Childhood trauma, resilience and the chance of being a crack cocaine user.

especially among females. The CTQ is a validated instrument to report this type of abuse as a self-report questionnaire, but since we had to interview the patients due to literacy issues, it may have interfered in this specific result.

According to our results, resilience scores are considerably decreased when subjects reported having suffered emotional abuse and neglect during childhood. These vulnerability factors may also increase the chance of using crack cocaine. Several hypotheses may explain this association. Experiences of traumatic events during childhood are strongly associated with higher levels of impulsivity and impairment on neuropsychological measures, which could increase vulnerability to drug experimentation $[34,35]$. Previous studies indicate that childhood trauma could influence the severity, prognosis and evolution of crack cocaine consumption [36]. Other studies emphasize this finding, showing that the negative quality of initial liaison with parental care may be associated with the onset of trauma-related disorders, such as substance abuse [37]. Saddichha et al. demonstrated in a distinct sample that patients who are emotionally abused during childhood have higher rates of crack cocaine use, as well as other stimulants [38]. Since early life development, there is an adaptation of the HPA-axis, and the resulting secretion of cortisol is responsible for metabolic, immunologic, cognitive and behavioral adjustments to stress. However, when stress becomes chronic early in life, there is an allostatic overload of the HPA axis, causing impairment to the mechanisms of adaptation to stress, thus promoting a maladaptive response and the consequent decrease of resilience, as well as a higher chance to develop addiction $[39,40]$.

Regarding the association between childhood trauma and specific aspects of resilience, individuals who reported to suffer emotional abuse and neglect during childhood had lower ability to solve problems, and less personal values that give meaning to life. Also, crack cocaine users reported to have higher scores of those types of trauma, as well as lower scores of factors 1 and 2 of the Resilience Scale when compared to controls. This finding among crack cocaine users could be explained by the impairment on executive functions among individuals with substance abuse disorder [41-43]. Cunha et al have demonstrated that crack cocaine users have an important deficit in decision making and that these cognitive changes may be associated with a social misfit [44].

Factor 3 of the Resilience Scale, which represents self-confidence and adaptation, was not significantly different between cases and controls. Considering that the involvement with psychoactive substances, in a psychoanalytical perspective, implies a narcissistic relationship with the drug itself and others, the feeling of self-confidence is expected among these patients [45]. This hypothesis is clinically represented by the need for urgent gratification anywhere and anytime, with orality and omnipotent components of personality [46]. Also, cluster B personality disorders, which include narcissistic personality disorder and antisocial personality disorders, have an important association with the expression of substance abuse. These include personality traits of high self-confidence, even when reality shows a more impaired patter of adaptation to environment and relationship to others [47]. A study conducted by Narvaez et al, showed that individuals with antisocial personality disorders had 10.29 times higher chance of being a crack cocaine user when compared to controls. Also, Albein-Urios et al have demonstrated in a neuroimaging study that cocaine users with cluster $B$ personality disorders have a disruptive way of interpreting emotions because of distinctive patterns of brain activation and connectivity during maintenance and reappraisal of negative emotions, and this is correlated to impulsivity and dysfunctional beliefs [48]. Therefore, the drug becomes more attractive in an attempt to regulate affect, be promptly gratified, and control aspects related to unrecognizable and uncomfortable feelings [49]. Despite the destructive aspect of drug use, it is also a way of finding adaptability among traumatic situations in order to promote immediate relief of negative feelings.

It is relevant to discuss that resilience, despite being an individual attribute, is not a static construct, and acts synergistically with environmental factors [50]. It is also a complex construct to measure, since it is related to individual characteristics, life experiences and environment [51]. The Resilience Scale assesses various dimensions including self-confidence, problem-solving skills, independence and 
determination. Presently, it is one of the few validated instruments that evaluate different aspects that determine the ability to overcome adversities throughout life. Thus, when resilience can override traumatic experiences, individuals are less vulnerable to further negative events, which may involve the severity of drug dependence. Therefore, the knowledge that resilience is decreased among crack cocaine users, and that the ones who suffered childhood trauma are even more vulnerable to life stress situations, could be an important issue to the development of strategies to increase resilience among this population.

Grassi-Oliveira et al have previously demonstrated that abuse and neglect during childhood are important risk factors for the occurrence of PTSD in female crack cocaine users, calling especial attention to the role of emotional neglect. This finding was confirmed in our study in a distinct sample. Results also showed a higher prevalence of PTSD in crack cocaine users than in controls. Although literature points toward a relationship between a diagnosis of PTSD and drug abuse, the results of this study show that childhood trauma increases the chance of developing crack cocaine dependence, regardless of whether they had developed PTSD or not. The fact that we could not find a direct association between PTSD and crack cocaine use could be due to the small sample size. Still, our results corroborate the hypothesis that abnormal development standards related to childhood trauma, especially neglect, may increase the chance to develop drug dependence. The understanding of risk factors within this group, as well as the identification of patients with low resilience may benefit future interventions, since this is a population with higher rates of PTSD. Thus, treatment for this disorder could increase the chance of abstinence and adherence to treatment.

The present study has a cross-sectional design and therefore does not allow for conclusions about causality and the prognosis of those individuals. Therefore, further investigations on this sample and others could indicate how childhood trauma and resilience may relate to time of relapse and adherence to treatment. Although the results of this study corroborate the hypothesis that childhood trauma and low resilience levels are vulnerability factors for the development of crack cocaine dependence, some of the analyses showed no statistical significance, probably due to the relatively small sample size, especially among controls. Also, crack cocaine patients were hospitalized during data collection, which may represent a higher severity of the disorder, therefore rendering limits in transposing these results for the outpatient population. In order to overcome cognitive impairment due to withdrawal symptoms, interviews were performed between the fifth and seventh day of hospitalization. However, interviews may have had an effect on the emotional stress, hampering access to specific trauma memories. Despite these limitations, the findings of this study originally provide fundamental information for understanding how resilience aspects are associated with crack cocaine dependence, as well as its association with childhood trauma and the development of PTSD. Understanding this model and vulnerabilities among this population could contribute to tailor more specific strategies of prevention and more effective intervention among crack cocaine users.

\section{Conclusion}

Crack cocaine users reported a higher score of emotional abuse, emotional neglect, physical abuse and physical neglect when compared to healthy controls. Also they reported to have less resilience in terms of ability to solve situations and personal values that give meaning to life, independence and determination, and it was inversely correlated to childhood trauma scores. Childhood trauma was significantly associated with a higher chance of developing crack cocaine dependence, regardless of whether the individual had developed PTSD or not.

\section{Aknowledgement}

This research was supported by the Brazilian Secretariat of Drug Policies (SENAD) and Fundo de Incentive à Pesquisa (FIPE).

\section{References}

1. Pedroso RS, Kessler F, Pechansky F (2013) Treatment of female and male inpatient crack users: a qualitative study. Trends Psychiatry Psychother 35: $36-45$

2. Chermack ST, Walton MA, Fuller BE, Blow FC (2001) Correlates of expressed and received violence across relationship types among men and women substance abusers. Psychol Addict Behav 15: 140-151.

3. Copeland-Linder N, Lambert SF, lalongo NS (2010) Community violence protective factors, and adolescent mental health: a profile analysis. J Clin Child Adolesc Psychol 39: 176-186.

4. Dias AC, Araújo MR, Dunn J, Sesso RC, de Castro V, et al. (2011) Mortality rate among crack/cocaine-dependent patients: a 12-year prospective cohort study conducted in Brazil. J Subst Abuse Treat 41: 273-278.

5. Karch SB (1999) Cocaine: history, use, abuse. J R Soc Med 92: 393-397.

6. Paim Kessler FH, Barbosa Terra M, Faller S, Ravy Stolf A, Carolina Peuker A et al. (2012). Crack users show high rates of antisocial personality disorder engagement in illegal activities and other psychosocial problems. Am J Addic 21: $370-380$.

7. Ribeiro M, Dunn J, Sesso R, Dias AC, Laranjeira R (2006) Causes of death among crack cocaine users. Rev Bras Psiquiatr 28: 196-202.

8. Ribeiro M, Dunn J, Sesso R, Lima MS, Laranjeira R (2007) Crack cocaine: a five-year follow-up study of treated patients. Eur Addict Res 13: 11-19.

9. Nappo SA (2014) Is there a crack epidemic among students in Brazil? comments on media and public health issues. In L. A. R. Zila M Sanchez (Ed.), (Vol. 28(9), pp. 1643-1649). Brazil: Cadernos de SaÃ ${ }^{\circ}$ e PÃ $\tilde{A}^{\circ}$ lica.

10. Wu NS, Schairer LC, Dellor E, Grella C (2010) Childhood trauma and health outcomes in adults with comorbid substance abuse and mental health disorders. Addict Behav 35: 68-71.

11. Khoury L, Tang YL, Bradley B, Cubells JF, Ressler KJ (2010) Substance use childhood traumatic experience, and Posttraumatic Stress Disorder in an urban civilian population. Depress Anxiety 27: 1077-1086.

12. Schiavone S, Jaquet V, Trabace L, Krause KH (2013) Severe life stress and oxidative stress in the brain: from animal models to human pathology. Antioxid Redox Signal 18: 1475-1490.

13. Ouimette P, Coolhart D, Funderburk JS, Wade M, Brown PJ (2007) Precipitants of first substance use in recently abstinent substance use disorder patients with PTSD. Addict Behav 32: 1719-1727.

14. Huang MC, Schwandt ML, Ramchandani VA, George DT, Heilig M, et al. (2012) Impact of multiple types of childhood trauma exposure on risk of psychiatric comorbidity among alcoholic inpatients. Alcohol Clin Exp Res 36: 1099-1107.

15. Tate SR, McQuaid JR, Brown SA (2005) Characteristics of life stressors predictive of substance treatment outcomes. J Subst Abuse Treat 29: 107-115.

16. Afful SE, Strickland JR, Cottler L, Bierut LJ (2010) Exposure to trauma: comparison of cocaine-dependent cases and a community-matched sample. Drug Alcohol Depend 112: 46-53.

17. Tull MT, Trotman A, Duplinsky MS, Reynolds EK, Daughters SB, et al. (2009) The effect of posttraumatic stress disorder on risk-taking propensity among crack/cocaine users in residential substance abuse treatment. Depress Anxiety 26: 1158-1164. Davydov DM, Stewart R, Ritchie K, Chaudieu I (2010) Resilience and mental health. Clin Psychol Rev 30: 479-495.

18. Herrenkohl TI (2013) Person-environment interactions and the shaping of resilience. Trauma Violence Abuse 14: 191-194.

19. Masten AS (2001) Ordinary magic. Resilience processes in development Am Psychol 56: 227-238. Sameroff AJ (2000) Developmental systems and psychopathology. Dev Psychopathol 12: 297-312. 
Citation: Sordi AO, Hauck S, Laitano H, Halpern S, Schuch S, et al. (2015) Childhood Trauma and Resilience: Vulnerabilities to Develop Crack/ Cocaine Dependence. J Alcohol Drug Depend 3: 227. doi:10.4172/23296488.1000227

20. Vanderbilt-Adriance E, Shaw DS (2008) Protective factors and the development of resilience in the context of neighborhood disadvantage. $\mathrm{J}$ Abnorm Child Psychol 36: 887-901.

21. Ungar M (2012) Researching and theorizing resilience across cultures and contexts. Prev Med 55: 387-389.

22. Wagnild GM, Young HM (1993) Development and psychometric evaluation of the Resilience Scale. J Nurs Meas 1: 165-178.

23. Windle G, Bennett KM, Noyes J (2011) A methodological review of resilience measurement scales. Health Qual Life Outcomes 9: 8.

24. Wagnild G (2009) A review of the Resilience Scale. J Nurs Meas 17: 105-113.

25. Wingo AP, Ressler, KJ, Bradley B (2014) Resilience characteristics mitigate tendency for harmful alcohol and illicit drug use in adults with a history of childhood abuse: a cross-sectional study of 2024 inner-city men and women. J Psychiatr Res 93-99.

26. von Diemen L, Kapczinski F, Sordi AO, de MagalhÃ£es Narvaez JC GuimarÃ£es LS, et al. (2013). Increase in brain-derived neurotrophic factor expression in early crack cocaine withdrawal. Int J Neuropsychopharmacol 1-8.

27. Kessler F, Cacciola J, Alterman A, Faller S, Souza-Formigoni ML, et al. (2012) Psychometric properties of the sixth version of the Addiction Severity Index (ASI-6) in Brazil. Rev Bras Psiquiatr 34: 24-33.

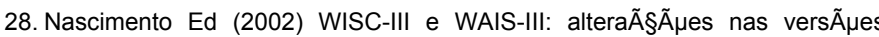
originais americanas decorrentes das adaptaÃßÃues para uso no Brasil. In V. L. M. d. Figueiredo (Ed.), (Vol. 15). Porto Alegre, Brazil.: Psicol. Reflex. Crit.

29. Amorin P (2000) Mini International Neuropsychiatric Interview (MINI): validation of a short structured diagnostic psychiatric interview 2: 106-115

30. Pesce RP, Assis SG, Avanci JQ, Santos NC, Malaquias JV, et al. (2005) [Cross-cultural adaptation, reliability and validity of the resilience scale]. Cad Saude Publica, 21: 436-448.

31. Grassi-Oliveira R, Stein LM, Pezzi JC (2006) [Translation and content validation of the Childhood Trauma Questionnaire into Portuguese language]. Rev Saude Publica 40: 249-255.

32. Francke ID, Viola TW, Tractenberg SG, Grassi-Oliveira R (2013) Childhood neglect and increased withdrawal and depressive severity in crack cocaine users during early abstinence. Child Abuse Negl 37: 883-889.

33. Narvaez JC, Magalhães PV, Trindade EK, Vieira DC, Kauer-Sant'anna M, et al. (2012) Childhood trauma, impulsivity, and executive functioning in crack cocaine users. Compr Psychiatry 53: 238-244.

34. Gould TJ (2010) Addiction and cognition. Addict Sci Clin Pract 5: 4-14

35. Wildschut M, Langeland W, Smit JH, Draijer N (2014) Survivors of early childhood trauma: evaluating a two-dimensional diagnostic model of the impact of trauma and neglect. Eur J Psychotraumatol 5.

36. Saddichha S, Fliers JM, Frankish J, Somers J, Schuetz CG, et al. (2014) Homeless and incarcerated: an epidemiological study from Canada. Int J Soc Psychiatry 60: 795-800.
37. Badanes LS, Watamura SE, Hankin BL (2011) Hypocortisolism as a potential marker of allostatic load in children: associations with family risk and internalizing disorders. Dev Psychopathol 23: 881-896.

38. McEwen BS (2003) Mood disorders and allostatic load. Biol Psychiatry 54: 200207.

39. Cunha PJ, Bechara A, de Andrade AG, Nicastri S (2011) Decision-making deficits linked to real-life social dysfunction in crack cocaine-dependent individuals. Am J Addict 20: 78-86.

40. Goldstein RZ, Volkow ND (2002) Drug addiction and its underlying neurobiological basis: neuroimaging evidence for the involvement of the frontal cortex. Am J Psychiatry 159: 1642-1652.

41. Narvaez JC, Jansen K, Pinheiro RT, Kapczinski F, Silva RA, et al. (2014) Psychiatric and substance-use comorbidities associated with lifetime crack cocaine use in young adults in the general population. Compr Psychiatry, 55(6), 1369-1376.

42. Cunha PJ, Bechara A, de Andrade AG, Nicastri S (2011) Decision-making deficits linked to real-life social dysfunction in crack cocaine-dependent individuals. Am J Addict 20: 78-86.

43. Belcher AM, Volkow ND, Moeller FG, Ferré S (2014) Personality traits and vulnerability or resilience to substance use disorders. Trends Cogn Sci 18: 211 217.

44. Ramos Sde P (2004) What can we learn from psychoanalysis and prospective studies about chemically dependent patients? Int J Psychoanal 85: 467-487.

45. Albein-Urios N, Martinez-Gonzalez JM, Lozano-Rojas O, Verdejo-Garcia A (2014) Executive functions in cocaine-dependent patients with Cluster B and Cluster $\mathrm{C}$ personality disorders. Neuropsychology 28: 84-90.

46. Albein-Urios N, Verdejo-Roman J, Soriano-Mas C, Asensio S, Martinez Gonzalez JM, et al. (2013) Cocaine users with comorbid Cluster B personality disorders show dysfunctional brain activation and connectivity in the emotional regulation networks during negative emotion maintenance and reappraisal. Eur Neuropsychopharmacol 23: 1698-1707.

47. Boys A, Marsden J, Strang J (2001) Understanding reasons for drug use amongst young people: a functional perspective. Health Educ Res 16: 457-469.

48. Hicks BM, Johnson W, Durbin CE, Blonigen DM, lacono WG, et al. (2014) Delineating selection and mediation effects among childhood personality and environmental risk factors in the development of adolescent substance abuse. J Abnorm Child Psychol 42: 845-859.

49. Back SE, Brady KT, Waldrop AE, Yeatts SD, McRae AL, et al. (2008) Early life trauma and sensitivity to current life stressors in individuals with and without cocaine dependence. Am J Drug Alcohol Abuse 34: 389-396.

50. Somaini L, Donnini C, Manfredini M, Raggi MA, Saracino MA, et al. (2011) Adverse childhood experiences (ACEs), genetic polymorphisms and neurochemical correlates in experimentation with psychotropic drugs among adolescents. Neurosci Biobehav Rev 35: 1771-1778.

51. Wrenn GL, Wingo AP, Moore R, Pelletier T, Gutman AR, et al. (2011) The effect of resilience on posttraumatic stress disorder in trauma-exposed innercity primary care patients. J Natl Med Assoc 103: 560-566.
Citation: Sordi AO, Hauck S, Laitano H, Halpern S, Schuch S, et al. (2015) Childhood Trauma and Resilience: Vulnerabilities to Develop Crack/Cocaine Dependence. J Alcohol Drug Depend 3: 227. doi:10.4172/23296488.1000227 